OPEN ACCESS

Edited by: Peter K. Giese, King's College London, United Kingdom

Reviewed by: Panteleimon Giannakopoulos, Université de Genève, Switzerland Lakshmi Rajagopal, Northwestern University, United States

*Correspondence: Jessica Peter jessica.peter@upd.unibe.ch

Received: 23 April 2019 Accepted: 25 June 2019 Published: 17 July 2019

Citation: Wagnon CC, Wehrmann K, Klöppel S and Peter J (2019) Incidental Learning: A Systematic Review of Its Effect on Episodic Memory Performance in Older Age. Front. Aging Neurosci. 11:173. doi: 10.3389/fnagi.2019.00173

\section{Incidental Learning: A Systematic Review of Its Effect on Episodic Memory Performance in Older Age}

\author{
Carole C. Wagnon, Katharina Wehrmann, Stefan Klöppel and Jessica Peter* \\ University Hospital of Old Age Psychiatry and Psychotherapy, University of Bern, Bern, Switzerland
}

Episodic memory is the capacity to encode, store, and retrieve information of specific past events. Several studies have shown that the decline in episodic memory accompanies aging, but most of these studies assessed memory performance through intentional learning. In this approach, the individuals deliberately acquire knowledge. Yet, another method to evaluate episodic memory performance-receiving less attention by the research community-is incidental learning. Here, participants do not explicitly intent to learn. Incidental learning becomes increasingly important over the lifespan, since people spend less time in institutions where intentional learning is required (e.g., school, university, or at work). Yet, we know little how incidental learning impacts episodic memory performance in advanced age. Likewise, the neural mechanisms underlying incidental learning in older age remain largely unknown. Thus, the immediate goal of this review was to summarize the existing literature on how incidental learning changes with age and how neural mechanisms map onto these age-related changes. We considered behavioral as well as neuroimaging studies using incidental learning paradigms (alone or in combination with intentional learning) to assess episodic memory performance in elderly adults. We conducted a systematic literature search on the Medline/PubMed, Cochrane, and OVID SP databases and searched the reference lists of articles. The search yielded 245 studies, of which 34 concerned incidental learning and episodic memory in older adults. In sum, these studies suggest that aging particularly affects episodic memory after incidental learning for cognitively demanding tasks. Monitoring deficits in older adults might account for these findings since cognitively demanding tasks need increased attentional resources. On a neuronal level, dysregulation of the default-mode-network mirrors monitoring deficits, with an attempt to compensate through increased frontal activity. Future (neuroimaging) studies should systematically evaluate retrieval tasks with diverging cognitive load and consider the influence of attention and executive functions in more detail.

Keywords: episodic memory, incidental learning, intentional learning, neural mechanisms, systematic review, aging 


\section{INTRODUCTION}

Whether we remember an episode or not depends on a set of mental processes that occur during encoding of this episode, its consolidation and its subsequent retrieval. The capacity to encode, store and retrieve information of personally experienced events is called episodic memory (Tulving, 2016). Episodic memory is essential for daily life and many studies have shown that its performance declines with advancing age (Shing et al., 2010; Nyberg et al., 2012). In the clinical context (e.g., in a memory clinic), episodic memory performance is typically tested by prompting participants to learn (i.e., encode) and retrieve a list of words (Rabin et al., 2005). In these tasks, older adults perform worse during the cognitive demanding free recall of words; that is, retrieval without cues (Rhodes et al., 2019). On the contrary, they perform better during the cognitively less demanding cued recall or recognition; that is, when they receive phonemic (i.e., first letter of the word) or semantic (i.e., the category) cues in case of cued recall or when they perform old/new memory judgements in case of recognition (Rhodes et al., 2019).

The initial encoding of information-be it a word list or other-happens either intentionally or incidentally (Figure 1). During intentional encoding, participants are instructed to memorize and deliberately direct attention to the stimuli (Ferr et al., 2015). During incidental learning, on the other hand, participants are not aware of the learning situation (i.e., they do not receive the instruction to memorize; McLaughlin, 1965). Their attention is directed to the stimuli because of another task (e.g., categorizing words according to certain criteria) and they encode stimuli "along the way" without the specific intention to do so (Zhou et al., 2012). Although incidental learning becomes increasingly relevant during aging-as people spent less time in institutions where intentional learning is required-most of episodic memory studies in older age focus on intentional learning. Thus, the influence of incidental learning on episodic memory performance in older age remains largely unknown.

One important theory for incidental learning is the level of processing framework (Craik and Lockhart, 1972): It postulates that deep (i.e., semantic) compared to shallow (i.e., perceptual) encoding benefits later retrieval (Galli, 2014) and that the retrieval can be further facilitated by using emotional content (either positive or negative; Ferr et al., 2015). In older adults, however, the facilitating effect of deep compared to shallow encoding is under debate. The processing deficit hypothesis states that cognitive processing resources are limited in older age and thus, older adults fail to use deeper encoding (Eysenck, 1974). Consequently, their memory performance is worse than in younger adults. On the contrary, the production deficiency hypothesis states that older adults are less likely to selfinitiate deep encoding (Mitchell and Perlmutter, 1986) but if they are told to use it, they perform comparable to younger adults (Light, 1991).

Irrespective of intentional or unintentional encoding, the interaction between the medial temporal lobe and the prefrontal cortex is crucial for later memory retrieval (Simons and Spiers, 2003)-at least at younger age. In the medial temporal lobe, the hippocampus and its surrounding areas are particularly important for memory consolidation and later retrieval (Simons and Spiers, 2003). The perirhinal cortex is specifically engaged in item encoding (that is, the what information; Davachi, 2006) and the right parahippocampal cortex is central for source and associative encoding (that is, contextual details like where, when, and how; Wheeler and Ploran, 2008). In the prefrontal cortex, the left dorsolateral part coordinates and controls the storing of brain activity patterns via monitoring and verification (Simons and Spiers, 2003), while the right prefrontal cortex is engaged during retrieval processes (Tulving, 2002). Additionally, the left inferior frontal gyrus, the left anterior prefrontal cortex, and the bilateral posterior middle frontal gyrus are active during demanding retrieval task (Wheeler and Ploran, 2008). These regions might provide additional resources to overcome task difficulty and thus, increased activity in these areas may represent compensation in older adults.

In general, aging is accompanied by functional alterations in the brain: Spreading activation (Cabeza, 2002), decreased activity in the medial temporal lobe (Reuter-Lorenz and Park, 2010), and default mode network (DMN) dysregulations (Grady et al., 2010). The DMN is a network of brain regions, which is typically inhibited during cognitive tasks and active during rest as well as mind wandering (Damoiseaux et al., 2008). In older adults, however, the DMN seems to be active also during cognitive tasks (Grady et al., 2010). Because the DMN usually inhibits regions related to attention and control (Broyd et al., 2009), a dysregulation causes higher vulnerability to distractors with a negative effect on memory performance (Lustig et al., 2010). The medial temporal lobe is also strongly affected by age-related alterations (e.g., hippocampal atrophy; Reuter-Lorenz and Park, 2010; Adler et al., 2018). Because of its crucial role for memory encoding, consolidation, and retrieval, these alterations strongly affect memory processing (Simons and Spiers, 2003; Davachi, 2006). For spreading activation, there are different theories: In view of the dedifferentiation theory, spreading activation is due to loss of specificity of neural representations in older adults (Baltes et al., 1980). In the increased noise theory, dedifferentiation is caused by alternations in neuronal transmission by dopaminergic decline leading to a less distinct neuronal representation (Bäckman et al., 2006). In the hemispheric asymmetry reduction in older adults (HAROLD) model, spreading activation is a compensatory mechanism. This theory proposes that older adults tend to show less left lateralized prefrontal activity than younger adults do, in order to meet task demands (Cabeza, 2002). Likewise, prefrontal over-activation is part of the posterioranterior shift in aging (PASA) model, which states that underactivation in posterior regions (i.e., the medial temporal lobe) is typically accompanied by prefrontal over-activation to aid performance (Davis et al., 2008). In a broader sense, the compensation-related utilization of neural circuits hypothesis (CRUNCH) states that older adults engage more neuronal circuits than younger adults do, in order to compensate their declining neuronal efficiency-especially for tasks requiring more effort and attention (Reuter-Lorenz and Cappell, 2008). A theory combining dedifferentiation, recruitment of alternative neuronal regions (i.e., prefrontal regions), decreased activation in the medial temporal lobe and DMN dysregulation is the scaffolding 


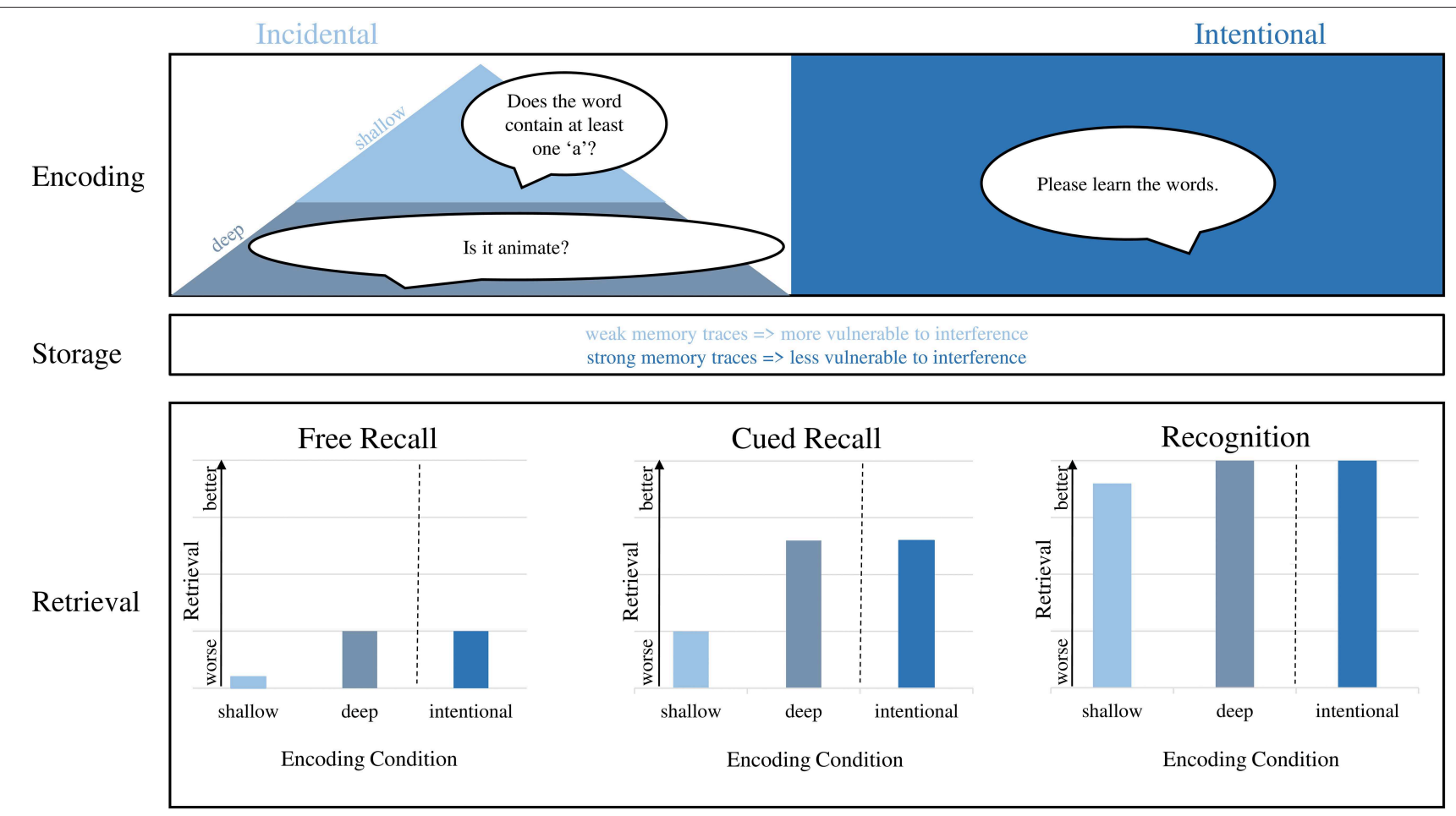

FIGURE 1 | The influence of incidental or intentional encoding on the three stages of episodic memory. During encoding, both deep incidental as well as intentional learning lead to a strong memory trace. During storage, weak memory traces following shallow encoding are more vulnerable to interference than strong memory traces after deep encoding. The disadvantage of shallow incidental encoding on later memory performance is mostly visible during free and cued recall and is almost eliminated during recognition.

theory of aging and cognition (STAC) (Reuter-Lorenz and Park, 2010). STAC postulates that these processes are adaptations of the brain to different neuronal age-related challenges like amyloid deposition, atrophy, white matter deterioration and dopamine receptor depletion (Park and Reuter-Lorenz, 2009).

Even though all these theories try to relate functional brain alterations to cognitive performance changes in older adults, none of them provides a specific statement for memory performance. It might be that age-related alterations like decreased activity in the medial temporal lobe as well as dysregulation of the DMN lead to an impaired episodic memory performance, while spreading activation, particularly in the prefrontal cortex, might be beneficial (since more attentional resources are available). Yet, these assumptions still need verification.

Thus, the goals of this review were to survey the literature on how incidental learning changes with advancing age as well as which neural correlates underlie incidental learning in elderly adults.

\section{METHODS}

For the present systematic review, we followed the Preferred Reporting Items for Systematic Reviews and Meta-Analysis (PRISMA) guidelines (Moher et al., 2009). We systematically searched for published studies in English with no date restriction across the following databases: Cochrane Central Register of Controlled Trials, MEDLINE, Books@Ovid, Ovid Journals, PsycARTICLES, Ovid MEDLINE(R), Epub, PsycINFO, and PSYNDEXplus. We used the following search terms: "incidental learning AND episodic memory AND older adults NOT child NOT animal NOT Alzheimer NOT MCI." For the neuroimaging part, we applied an additional literature search with the following search terms: "brain AND age AND [incidental/level of processing/categorical decision] NOT children NOT patients NOT working memory NOT Alzheimer NOT MCI NOT animals NOT dementia NOT Parkinson NOT infants NOT incidental findings NOT alcohol NOT stimulation NOT motor NOT STROOP NOT depression NOT syndrome NOT smoking NOT stress NOT diabetes NOT tinnitus NOT eye-tracking."

To be eligible for inclusion, studies needed to: (1) investigate incidental learning (preferably, but not necessarily, in conjunction with intentional learning) in cross-sectional or longitudinal designs, (2) focus on episodic memory, (3) include older adults or compare older adults' performance to that of younger participants. To reduce the risk of bias, two authors (CW and KW) independently screened abstracts and titles and analyzed studies that met inclusion criteria, as suggested by the PRISMA guidelines. We also screened the reference lists of included studies to identify any additional studies.

The search yielded 726 studies, of which 33 met criteria for the final review. Figure 2 reports the four phases of the selection 


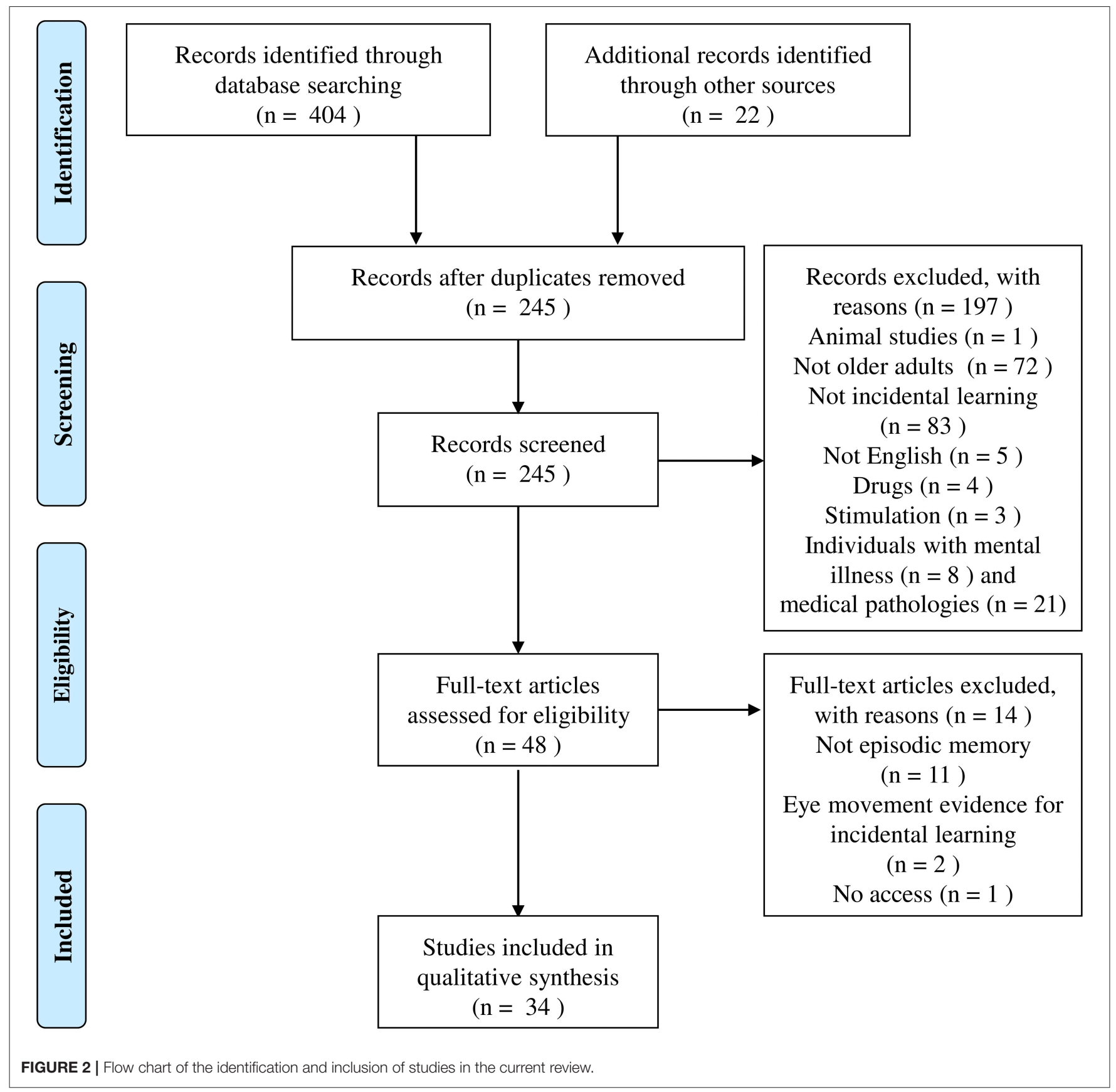

process (identification, screening, eligibility, and inclusion-as suggested by PRISMA).

\section{RESULTS}

Table 1 gives an overview on the included studies (see also Table 2 for a summary on the behavioral findings). The majority of these studies found comparable or decreased episodic memory performance in older adults compared to younger participants, while only one study evidenced superior performance. Agerelated changes were more evident in retrieval tasks with high cognitive load (i.e., free recall) than in less demanding retrieval tasks (i.e., recognition). For less demanding tasks, older adults showed higher false alarm rates compared to younger adults but hit rates and reaction times were comparable. Fifteen studies examined age-related changes in neural correlates of incidental learning and observed less activity in hippocampal regions as well as more activity in right frontal regions. Likewise, regions related to the DMN tended to be more active in older adults compared to younger adults (see Figure 3 for a summary). In the following, we will describe the reviewed studies in more detail. We will first concentrate on studies, which applied incidental learning 
TABLE 1 | Overview of all included studies.

\begin{tabular}{|c|c|c|c|c|c|c|c|}
\hline \multirow[b]{2}{*}{ References } & \multicolumn{6}{|c|}{ Methods } & \multirow[b]{2}{*}{ Results } \\
\hline & Participants & Condition & Imaging & Stimuli & Encoding type & Retrieval & \\
\hline Eysenck, 1974 & $\begin{array}{l}N=100 \\
(n=50 \circ, n=50 \mathrm{y})\end{array}$ & $\begin{array}{l}\text { Incidental + } \\
\text { intentional }\end{array}$ & No & Words & Deep and shallow & Free recall & $\begin{array}{l}y=0 \text { for shallow items } \\
y>0 \text { for deep items } \\
y>0 \text { for intentional condition }\end{array}$ \\
\hline Mason, 1979 & $\begin{array}{l}N=498 \\
(n=190 \mathrm{o}, n=136 \\
\mathrm{mo}, n=172 \mathrm{y})\end{array}$ & $\begin{array}{l}\text { Incidental + } \\
\text { intentional }\end{array}$ & No & Words & Deep and shallow & $\begin{array}{l}\text { Free recall and } \\
\text { recognition }\end{array}$ & $\begin{array}{l}0=y \text { for shallow items } \\
y>0 \text { for deep items } \\
y>0 \text { for intentional condition }\end{array}$ \\
\hline Duchek, 1984 & $\begin{array}{l}N=64 \\
(n=320, n=32 \mathrm{y})\end{array}$ & Incidental & No & Words & Deep and shallow & Cued recall & $y>0$ for deep and shallow condition \\
\hline $\begin{array}{l}\text { Mitchell and Perlmutter, } \\
1986\end{array}$ & $\begin{array}{l}N=64 \\
(n=32 \circ, n=32 y)\end{array}$ & $\begin{array}{l}\text { Incidental + } \\
\text { intentional }\end{array}$ & No & Words & Deep and shallow & $\begin{array}{l}\text { Free recall and } \\
\text { recognition }\end{array}$ & $\begin{array}{l}y=0 \text { for shallow and deep condition } \\
y>0 \text { for intentional condition }\end{array}$ \\
\hline Mitchell, 1989 & $\begin{array}{l}N=96 \\
(n=48 y, n=480)\end{array}$ & Incidental & No & Line drawings & Picture-naming & $\begin{array}{l}\text { Free Recall and } \\
\text { recognition }\end{array}$ & $y>0$ \\
\hline Stebbins et al., 2002 & $\begin{array}{l}N=30 \\
(n=15 \mathrm{y}, n=150)\end{array}$ & Incidental & fMRI & Words & Deep and shallow & None & $\begin{array}{l}y>0 \text { (activity in the left superior and } \\
\text { middle frontal gyrus) }\end{array}$ \\
\hline Daselaar et al., 2003 & $\begin{array}{l}N=60 \\
(n=20 y, n=400)\end{array}$ & Incidental & fMRI & Words & $\begin{array}{l}\text { Emotional and } \\
\text { shallow }\end{array}$ & Recognition & $\begin{array}{l}y>0 \text { (activity in the } \\
\text { perirhinal/parahippocampal region) } \\
y<0 \text { (activity in the right } \\
\text { prefrontal cortex) }\end{array}$ \\
\hline Aine et al., 2005 & $\begin{array}{l}N=20 \\
(n=10 y, n=10 \circ)\end{array}$ & Incidental & MEG & Words & Deep & Recognition & $\begin{array}{l}y=0 \\
y=0 \text { (time courses in the prefrontal } \\
\text { cortex) } \\
y<0 \text { (higher amplitudes in the } \\
\text { prefrontal cortex) }\end{array}$ \\
\hline Gutchess et al., 2005 & $\begin{array}{l}N=27 \\
(n=14 \mathrm{y}, n=13 \mathrm{o})\end{array}$ & Incidental & fMRI & Pictures (scenes) & Shallow & Recognition & $\begin{array}{l}y=0 \\
y>0 \text { (activity in both parahippocampi) } \\
y<0 \text { (activity in middle frontal cortex } \\
\text { and stronger negative connectivity } \\
\text { between parahippocampal and inferior } \\
\text { frontal cortex) }\end{array}$ \\
\hline Troyer et al., 2006 & $\begin{array}{l}N=104 \\
(n=40 y, n=64 \text { o) }\end{array}$ & $\begin{array}{l}\text { Incidental + } \\
\text { intentional }\end{array}$ & No & Names and faces & Deep and shallow & $\begin{array}{l}\text { Free recall and } \\
\text { recognition }\end{array}$ & $\begin{array}{l}y=0 \text { for incidental } \\
y>0 \text { for intentional }\end{array}$ \\
\hline $\begin{array}{l}\text { Kensinger and } \\
\text { Schacter, } 2008\end{array}$ & $\begin{array}{l}N=37 \\
(n=17 y, n=20 \text { o) }\end{array}$ & Incidental & fMRI & Pictures (objects) & Deep & Recognition & $\begin{array}{l}y>0 \text { (negative and neutral items; } \\
\text { proportion of correctly recognized } \\
\text { "same" items) } \\
y>0 \text { (activity in the hippocampus and } \\
\text { the parahippocampal gyrus) } \\
y<0 \text { (activity in the medial, middle and } \\
\text { inferior frontal gyrus, the middle temporal } \\
\text { gyrus, and anterior cingulate gyrus) }\end{array}$ \\
\hline
\end{tabular}




\begin{tabular}{|c|c|c|c|c|c|c|c|}
\hline Murty et al., 2009 & $\begin{array}{l}N=60 \\
(30 \mathrm{y}, n=30 \text { o) }\end{array}$ & Incidental & fMRI & Emotional scenes & Deep & Recognition & $\begin{array}{l}y>0 \text { (accuracy and reaction times) } \\
y>0 \text { (activity in hippocampus and } \\
\text { amygdala) } \\
y<0 \text { (activity in ventral visual stream, } \\
\text { prefrontal, and parietal cortex) }\end{array}$ \\
\hline $\begin{array}{l}\text { Naveh-Benjamin et al., } \\
2009\end{array}$ & $\begin{array}{l}N=47 \\
(n=24 \mathrm{y}, n=230) \\
N=84 \\
(n=42 \mathrm{y}, n=42 \mathrm{o})\end{array}$ & $\begin{array}{l}\text { Incidental + } \\
\text { intentional }\end{array}$ & No & Names and faces & $\begin{array}{l}\text { Face-name matching } \\
\text { or association }\end{array}$ & Recognition & $\begin{array}{l}y=0 \text { for intentional except for } \\
\text { associations (here, } y>0 \text { ) } \\
y>0 \text { for incidental }\end{array}$ \\
\hline Fischer et al., 2010 & $\begin{array}{l}N=45 \\
(n=24 \mathrm{y}, n=210)\end{array}$ & Incidental & fMRI & Emotional faces & Emotional & Recognition & $\begin{array}{l}y=0 \text { (hits) } \\
y<0 \text { (false alarm and discrimination) } \\
y>0 \text { for fearful vs. neutral faces (activity } \\
\text { in right amygdala and bilateral } \\
\text { hippocampus) } \\
y<0 \text { for fearful vs. neutral faces (activity } \\
\text { in left insular cortex and right superior } \\
\text { frontal gyrus) }\end{array}$ \\
\hline Plancher et al., 2010 & $\begin{array}{l}N=160(n=82 \mathrm{y}, n \\
=78 \text { o) }\end{array}$ & $\begin{array}{l}\text { Incidental + } \\
\text { intentional }\end{array}$ & No & $\begin{array}{l}\text { Urban environment } \\
\text { in VR }\end{array}$ & Driving in VR & $\begin{array}{l}\text { Free recall and } \\
\text { recognition }\end{array}$ & $\begin{array}{l}y<0 \text { for incidental "what" details } \\
y=0 \text { for intentional "what" details and } \\
\text { for incidental "when" details } \\
y>0 \text { for 'where' details in } \\
\text { both conditions }\end{array}$ \\
\hline Cho et al., 2012 & $\begin{array}{l}N=63 \\
(n=40 y, n=23 \text { o) }\end{array}$ & Incidental & fMRI & Words (auditory) & Deep & None & $\begin{array}{l}y>0 \text { (inferior frontal gyrus and middle } \\
\text { temporal gyrus) } \\
y<0 \text { (ventromedial prefrontal cortex, } \\
\text { right middle, and inferior frontal gyrus, } \\
\text { bilateral precuneus, left middle, and } \\
\text { superior temporal gyrus, bilateral } \\
\text { parahippocampus, and bilateral } \\
\text { posterior cingulate cortex) }\end{array}$ \\
\hline Sambataro et al., 2012 & $\begin{array}{l}N=44 \\
(n=22 \mathrm{y}, n=22 \mathrm{o})\end{array}$ & Incidental & fMRI & Pictures (scenes) & Shallow & Recognition & $\begin{array}{l}y>0 \text { (left hippocampus) } \\
y<0 \text { (bilateral prefrontal cortex, } \\
\text { precuneus, temporo-parietal junction, } \\
\text { and posterior cingulate regions) }\end{array}$ \\
\hline Waring et al., 2013 & $\begin{array}{l}N=37 \\
(n=19 y, n=180)\end{array}$ & Incidental & fMRI & Emotional scenes & Emotional & Recognition & $\begin{array}{l}y>0 \\
y<0 \text { (stronger connectivity in frontal } \\
\text { regions and from frontal regions to } \\
\text { medial temporal lobe structures) }\end{array}$ \\
\hline Greve et al., 2014 & $\begin{array}{l}N=48 \\
(n=24 y, n=240)\end{array}$ & $\begin{array}{l}\text { Incidental + } \\
\text { intentional }\end{array}$ & sMRI & Pictures (objects) & Shallow & Recognition & $y>0$ \\
\hline Martins et al., 2014 & $\begin{array}{l}N=42 \\
(n=28 y, N=140)\end{array}$ & Incidental & fMRI & Words & Deep and shallow & None & $\begin{array}{l}y>0 \text { for deep vs. shallow encoding } \\
\text { (left prefrontal cortex, left posterior } \\
\text { cingulate cortex, left precuneus } \\
y<\text { o for shallow vs. deep encoding } \\
\text { (left posterior cingulate cortex) }\end{array}$ \\
\hline Kalenzaga et al., 2015 & $\begin{array}{l}N=35 \\
(n=19 y, n=16 \text { o) }\end{array}$ & Incidental & fMRI & Sentences & $\begin{array}{l}\text { Self-referential and } \\
\text { imagery }\end{array}$ & Free recall & $\begin{array}{l}y=0 \text { for item memory } \\
y>0 \text { for source memory } \\
y<0 \text { (activity in fronto-parietal network) }\end{array}$ \\
\hline
\end{tabular}


TABLE 1 | Continued

\begin{tabular}{|c|c|c|c|c|c|c|c|}
\hline Carr et al., 2015 & $\begin{array}{l}N=71 \\
(n=47 \mathrm{y}, n=24 \mathrm{o})\end{array}$ & Incidental & No & Faces & $\begin{array}{l}\text { Similarity and } \\
\text { distinctiveness }\end{array}$ & Recognition & $\begin{array}{l}y>0 \text { for distinctiveness } \\
y=0 \text { for similarity }\end{array}$ \\
\hline Lindner et al., 2015 & $\begin{array}{l}N=55 \\
(n=36 \mathrm{y}, n=190) \\
N=66 \\
(n=26 \mathrm{y}, n=300) \\
N=43 \\
(n=24 \mathrm{y}, n=190)\end{array}$ & $\begin{array}{l}\text { Incidental + } \\
\text { intentional }\end{array}$ & No & Sentences & $\begin{array}{l}\text { Source and } \\
\text { destination }\end{array}$ & Recognition & $\begin{array}{l}y=0 \text { for source and destination in both } \\
\text { conditions }\end{array}$ \\
\hline Ramanoël et al., 2015 & $\begin{array}{l}N=24 \\
(n=12 \mathrm{y}, n=120)\end{array}$ & Incidental & $\mathrm{fMRl}$ & Pictures (scenes) & Shallow & None & $\begin{array}{l}y<0 \text { (right middle frontal gyrus, right } \\
\text { inferior parietal lobule, left inferior parietal } \\
\text { lobule, and left middle temporal gyrus) }\end{array}$ \\
\hline Saverino et al., 2016 & $\begin{array}{l}N=34 \\
(n=16 y, n=180)\end{array}$ & Incidental & fMRI & $\begin{array}{l}\text { Pictures } \\
\text { (house/objects) }\end{array}$ & Shallow and deep & Recognition & $\begin{array}{l}y>0 \text { for association } \\
y=0 \text { for categorization } \\
y=0 \text { (parahippocampal gyrus, inferior } \\
\text { parietal lobe) } \\
y>0 \text { (precentral gyrus, inferior temporal } \\
\text { gyrus, posterior cingulate } \\
\text { gyrus, precuneus) }\end{array}$ \\
\hline $\begin{array}{l}\text { Wang and Giovanello, } \\
2016\end{array}$ & $\begin{array}{l}N=52 \\
(n=29 y, n=230)\end{array}$ & $\begin{array}{l}\text { Incidental + } \\
\text { intentional }\end{array}$ & fMRI & Sentences & Reading & Recognition & $\begin{array}{l}y=0 \text { for incidental } \\
y=0 \text { for intentional } \\
y=0 \text { (hippocampus and } \\
\text { perirhinal cortex })\end{array}$ \\
\hline Fu et al., 2017 & $\begin{array}{l}N=46 \\
(n=23 \mathrm{y}, n=230)\end{array}$ & Incidental & No & Words & Deep and shallow & Recognition & $\begin{array}{l}y>0 \text { for shallow } \\
y=0 \text { for deep }\end{array}$ \\
\hline $\begin{array}{l}\text { Kontaxopoulou et al., } \\
2017\end{array}$ & $\begin{array}{l}N=47 \\
(n=27 \mathrm{y}, n=200)\end{array}$ & $\begin{array}{l}\text { Incidental + } \\
\text { intentional }\end{array}$ & No & $\begin{array}{l}\text { Computer- } \\
\text { generated items } \\
\text { (i.e., speed limit } \\
\text { signs), words, and } \\
\text { geometric figures }\end{array}$ & $\begin{array}{l}\text { Computer-generated } \\
\text { driving task, verbal } \\
\text { learning, and } \\
\text { visuospatial memory }\end{array}$ & $\begin{array}{l}\text { Free Recall and } \\
\text { recognition }\end{array}$ & $\begin{array}{l}y>0 \text { for incidental free recall, intentional } \\
\text { visuospatial free recall, and incidental } \\
\text { recognition } \\
y=0 \text { for intentional verbal free recall, } \\
\text { intentional verbal recognition, and } \\
\text { incidental visuospatial recognition }\end{array}$ \\
\hline François et al., 2018 & $\begin{array}{l}N=39(n=20 \mathrm{y}, n \\
=190)\end{array}$ & Incidental & fMRI & Drawings & Deep & Recognition & $\begin{array}{l}y>0 \text { except for reaction times or new } \\
\text { items (here, } y=0 \text { ) } \\
y<0 \text { (right frontal areas and regions } \\
\text { associated with the DMN) }\end{array}$ \\
\hline Hämmerer et al., 2018 & $\begin{array}{l}N=50(n=28 \mathrm{y}, n \\
=220)\end{array}$ & Incidental & sMRI & Pictures (scenes) & Shallow & Recognition & $\begin{array}{l}y=o(\text { hits, false alarms) } \\
y=o \text { (volume of the locus coeruleus) }\end{array}$ \\
\hline Hennessee et al., 2018 & $\begin{array}{l}N=66 \\
(n=33 y, n=33 \text { o) }\end{array}$ & $\begin{array}{l}\text { Incidental + } \\
\text { intentional }\end{array}$ & No & $\begin{array}{l}\text { Words with color } \\
\text { and point-value }\end{array}$ & $\begin{array}{l}\text { Binding of color and } \\
\text { point-value or word } \\
\text { learning }\end{array}$ & Recognition & $\begin{array}{l}y>0 \text { for intentional } \\
y=0 \text { for incidental }\end{array}$ \\
\hline Lugtmeijer et al., 2019 & $\begin{array}{l}N=59 \\
(n=30 y, n=290)\end{array}$ & Incidental & No & Pictures (objects) & $\begin{array}{l}\text { Object-location } \\
\text { binding }\end{array}$ & Recognition & $y>0$ for location \\
\hline Meade et al., 2018 & $\begin{array}{l}N=144 \\
(n=72 \mathrm{y}, n=72 \mathrm{o})\end{array}$ & Incidental & No & Words (objects) & $\begin{array}{l}\text { Drawing, writing, or } \\
\text { listing characteristics } \\
\text { of the objects }\end{array}$ & $\begin{array}{l}\text { Free recall and } \\
\text { recognition }\end{array}$ & $\begin{array}{l}y>0 \text { except for encoding via drawing } \\
\text { (here, } y=0 \text { for hit rate) }\end{array}$ \\
\hline
\end{tabular}

y, young; mo, middle-old; o, old; fMRI, functional Magnetic Resonance Imaging; sMRI, structural Magnetic Resonance Imaging; MEG, Magnetoencephalography; VR, virtual reality; DMN, default mode network 
TABLE 2 | Summary of behavioral findings when comparing episodic memory performance following incidental or intentional learning in groups of healthy young and elderly adults.

\begin{tabular}{|c|c|c|c|c|}
\hline Performance measure & & \multicolumn{3}{|c|}{ Comparison of episodic memory performance } \\
\hline Cued recall & Incidental & Duchek (shallow + deep) & & \\
\hline Recognition (hit rate) & Incidental & $\begin{array}{l}\text { Mason (deep) } \\
\text { Naveh-Benjamin } \\
\text { Carr } \\
\text { Saverino } \\
\text { Fu (shallow) } \\
\text { Francois } \\
\text { Waring } \\
\text { Greve } \\
\text { Meade } \\
\text { Kontaxopoulou } \\
\text { Murty } \\
\text { Kensinger }\end{array}$ & $\begin{array}{l}\text { Mitchell } \\
\text { Mitchell \& Perlmutter } \\
\text { Daselaar } \\
\text { Sambatoro } \\
\text { Carr } \\
\text { Kalenzaga } \\
\text { Lindner } \\
\text { Fu (deep) } \\
\text { Lugtmeijer } \\
\text { Hennessee } \\
\text { Hämmerer } \\
\text { Gutchess } \\
\text { Aine } \\
\text { Troyer } \\
\text { Wang } \\
\text { Meade } \\
\text { Kontaxopoulou } \\
\text { Fischer } \\
\text { Kensinger }\end{array}$ & \\
\hline Recognition (false alarm rate) & Intentional & & Hennessee & \\
\hline Recognition (reaction times) & Incidental & & $\begin{array}{l}\text { Daselaar } \\
\text { Francois } \\
\text { Aine }\end{array}$ & Murty \\
\hline
\end{tabular}

Please note that some studies applied several experiments (e.g., Plancher et al., 2010). For false alarms, lower false alarm rates indicate better performance.

only, afterwards review studies that applied both incidental and intentional learning and finally, we will focus on studies that investigated the neural correlates of incidental learning in older age.

Duchek (1984) tested incidental learning in a cued recall task after a semantic (e.g., "is it a type of bird?") or rhyme (e.g., "does it rhyme with care?") categorization task. Older adults remembered fewer items than younger adults did and were overall slower in their reactions. Younger participants remembered significantly more yes-responses than no-responses and were superior in recall of semantically encoded words.
Kalenzaga et al. (2015) found no significant age difference in free recall of autobiographical memories. In their task, participants had to fill in sentences with one missing word and think about an experience they made on this topic.

Several studies investigated the effect of deep vs. shallow encoding on free recall of words but yielded contradicting results. Eysenck (1974) and Mason (1979) found comparable memory performance in both age groups after shallow encoding but inferior retrieval in older adults following deep encoding. In contrast, Mitchell and Perlmutter (1986) as well as Fu et al. (2017) found elderly adults to benefit from deep encoding with comparable performance during retrieval or recognition. 


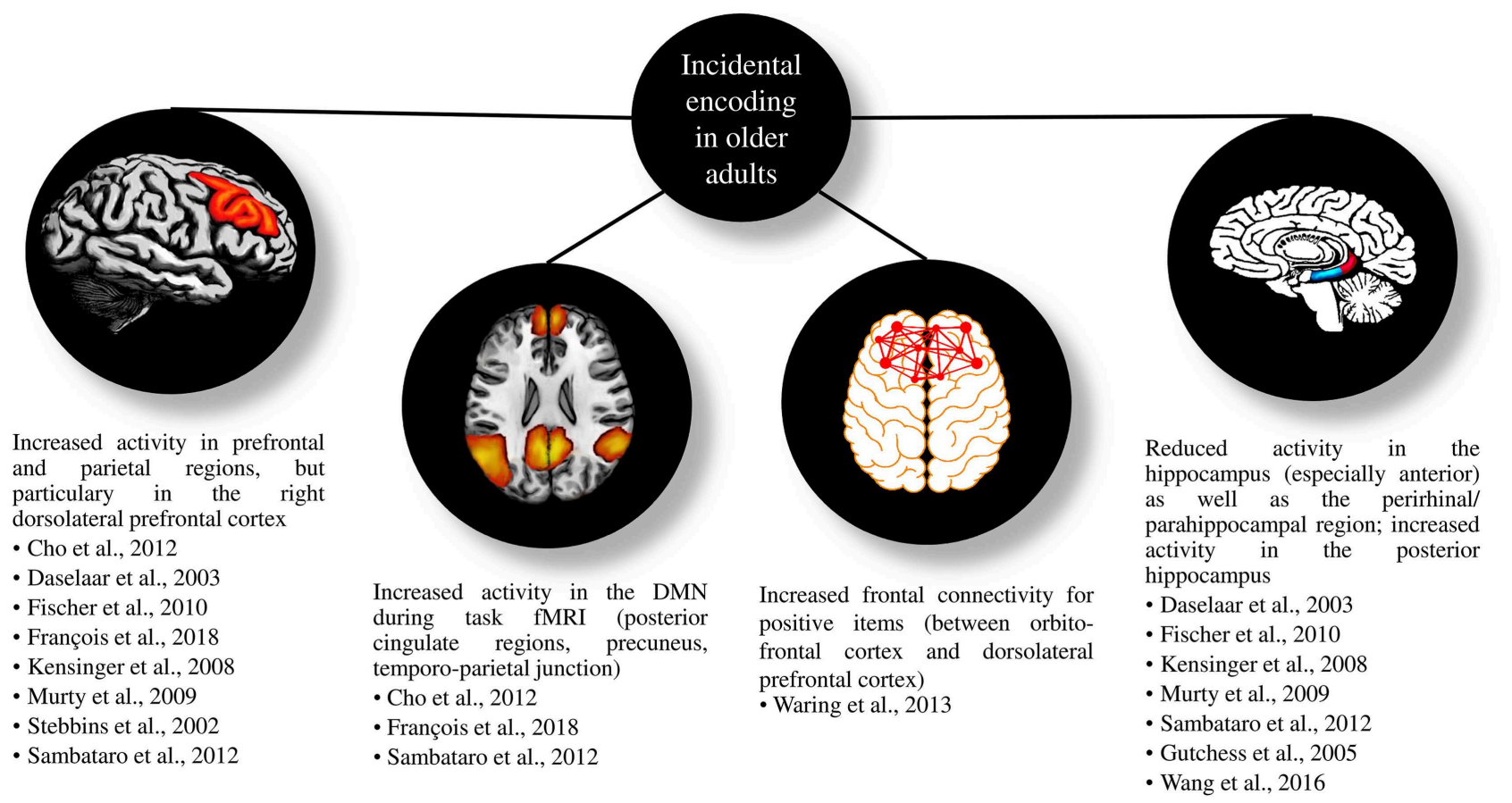

FIGURE 3 | Figure of the most important functional magnetic resonance imaging results of the reviewed studies when applying incidental encoding in older compared to younger adults. DMN, default mode network; fMRI, functional Magnetic Resonance Imaging.

However, the effect sizes in these studies were small $(d=0.25-$ 0.34), with the highest effect size observed by Eysenck (1974). All of these studies additionally applied intentional encoding and constantly found younger adults outperforming older adults at retrieval.

Daselaar et al. (2003) applied encoding and recognition of words rated according to their pleasantness (i.e., is the word pleasant or unpleasant). During recognition, the participants had to decide if a given word was old or new. The authors did not find any significant difference between young and elderly individuals regarding hit rate or reaction times.

Similarly, Sambataro et al. (2012) found no significant age difference in recognition accuracy. In their task, the participants had to decide if a given image represented an indoor or an outdoor scene and in a subsequent recognition task, they had to recognize if the images were old or new. On the contrary, Murty et al. (2009) found superior performance of younger adults compared to older adults for accuracy and reaction times during a similar task (i.e., recognition of indoor and outdoor scenes).

Mitchell (1989) examined the effect of incidental learning on subsequent free recall and recognition. Participants had to name pictures, which appeared on a projection screen and, after a short delay, recalled the names of the pictures in writing and performed an old/new recognition task. Younger participants freely recalled more pictures and had a lower false alarm rate during recognition compared to older participants, but both groups performed comparable for hit rates.

Carr et al. (2015) led participants decide if several faces were distinct or similar to a given face. In the subsequent recognition task, the group of younger participants outperformed the group of older adults only for faces studied in the distinctness task but not for faces studied in the similarity task. In a similar approach, Fischer et al. (2010) led participants decide if a face was fearful or neutral. They found no age effect for hits in the subsequent recognition task, but younger adults outperformed older adults with lower false alarm rates.

François et al. (2018) led participants decide if a given line drawing would fit into a shoebox or not. In the subsequent recognition task (remember/know/new), they found no significant differences in reaction times between both groups. However, they observed lower hit rates for remember items in older adults compared to younger adults and an increased false alarm rate for both remember and know items. No significant differences were found for items declared as new (neither hit rate nor false alarm rate). (Kensinger and Schacter, 2008) performed a similar study by asking participants if several objects would fit in a file cabinet drawer or not. Older adults showed lower hit rates, particularly for negative and neutral items. However, they recognized positive items comparable to younger adults. Thus, older adults remember the positive material better, indicating a well-preserved positivity effect in this population (Carstensen and Mikels, 2005).

Comparable to Daselaar et al. (2003), Sambataro et al. (2012), Kalenzaga et al. (2015), and Lugtmeijer et al. (2019) found no age-related difference in recognition performance after incidental learning. Similarly, Aine et al. (2005), Gutchess et al. (2005), and Hämmerer et al. (2018) found no evidence of a recognition deficit in older adults. In contrast, Waring et al. (2013), Greve et al. 
(2014), and Meade et al. (2018) evinced impaired recognition performance in older adults after both incidental and intentional encoding. Meade et al. (2018) compared the effect of different encoding strategies on word retrieval. They asked participants to draw the to-be-remembered words, to create a mental image of the object, or to write down as many characteristics of the object as possible. Only drawing of the object increased performance in older adults in a way that they performed similarly to younger adults during recognition.

Saverino et al. (2016) tested item and associative encoding under incidental conditions. For item encoding, participants indicated if the style of a given house on a picture was modern or traditional. During associative encoding, they decided if "based on the style of an object, would it be likely to be found in the house." Later on, they administered an old/new recognition task. The authors found no significant age differences for item recognition but older adults performed significantly worse for associative recognition with a lower number of hits and a higher false alarm rate. This supports an associative memory deficit in older adults, which was also found in a study by Naveh-Benjamin et al. (2009). Here, participants were either asked to remember face-name pairs (i.e., intentional condition) or to rate whether a name fits to a face (i.e., incidental condition). The authors found that younger and older adults had comparable memory performance for faces and names in isolation, irrespective of incidental, or intentional learning. However, an age-related deficit appeared specific to associations under intentional-but not incidental-learning. This was due to a higher false alarm rate during the associative task.

Troyer et al. (2006) conducted two experiments with younger and older adults. They applied three different levels of incidental encoding (physical, phonematic, semantic) to surnames or facename pairs and administered intentional learning, too. Younger participants outperformed older ones during free recall as well as recognition of intentionally learned names but showed equal performance during free recall and recognition of intentionally learned face-name-pairs. For incidental learning, both groups performed equally well during free recall and recognition of both names and face-name pairs. On the contrary, Wang and Giovanello (2016) found no significant age difference for incidental encoding of word pairs that appeared together during a sentence-reading task.

In a very recent study, Hennessee et al. (2018) asked participants to imagine being in different states of physiological need (e.g., hunger, thirst) as well as being in different locations (e.g., kitchen, forest). Then, they should examine the congruence of an item with the state of need and to rate how much they want to have this item right now. After a delay, they applied an old/new recognition task. The authors found comparable performance for hit rates but older adults showed a significantly higher false alarm rate. In a second experiment, they showed words in different colors, associated with different point-values. They asked the participants to memorize the words but they did not ask them to memorize the color nor the value. Younger adults outperformed older individuals for low value items but not for high value items. The authors found no significant age difference for incidental learning (color).
In a study by Lindner et al. (2015), participants had to listen to sentences and to encode the source (i.e., who said something) or the destination (i.e., to whom was said something); thus they encoded the where details. During retrieval, they had to decide whether sentences were spoken by/to a person and if a sentence was old or new. They were either made aware of the upcoming memory test (i.e., intentional learning) or not (i.e., incidental learning). The authors observed no significant differences in recognition performance between both age groups in either learning condition. Similarly, Plancher et al. (2010) were interested in where as well as in what and when details. They asked participants to drive through a virtual town and to pay attention to the surroundings (incidental condition) or to try to remember the itinerary (intentional condition). After a short delay, they first performed a free recall on what, where, and when details associated with the itinerary and afterwards applied a recognition task in which the participants decided which item among three different ones appeared in the task. They found an increased memory performance among older adults under incidental learning and comparable performance under intentional learning (but only for what details). In contrast to Lindner et al. (2015), older adults scored less on recall of where information, both under intentional and incidental encoding using a free recall task. For the when information, young participants outperformed older ones under intentional-but not incidental-encoding. Likewise, Kontaxopoulou et al. (2017) examined age effects for incidental encoding of what details during a driving simulator task. They also applied intentional encoding, by asking participants to learn line drawings in different spatial locations as well as words. In contrast to the results of Plancher et al. (2010), older adults showed worse recall and recognition performance for incidentally learned what details. For intentionally learned items, only the free recall of line drawings revealed significant age differences as older males performed worse than younger males did. Taken together, the difficulty of the retrieval task seems to explain age-related differences rather than the content of the remembered details (i.e., what, where, or when information).

In the following, we will describe neuroimaging studies that applied incidental encoding in young and elderly adults (see Figure 3 for a summary of the findings).

Daselaar et al. (2003), Gutchess et al. (2005), Kensinger and Schacter (2008), Murty et al. (2009), Fischer et al. (2010), and Sambataro et al. (2012) found reduced activity in medial temporal lobe structures as well as stronger activity in frontal regions in older adults, which is in line with the PASA model. According to the model, under-activation in posterior regions in older adults is typically associated with prefrontal over-activation; the latter representing additional resources to overcome cognitive impairment (Davis et al., 2008). Murty et al. (2009) investigated brain activity differences between younger and older adults during encoding and retrieval of indoor and outdoor scenes. They found decreased activity in the hippocampus and the amygdala accompanied by increased activity in frontal and parietal cortices during encoding and retrieval in older adults. Gutchess et al. (2005) tested the contrast between remembered and forgotten items during the 
encoding of indoor and outdoor scenes. Both age groups showed comparable activity in bilateral inferior frontal regions, regions of the dorsal and ventral stream, and fusiform areas. Older adults exhibited less activity in the parahippocampus (both sides) but more activity in the left middle frontal cortex compared to younger adults. Increased activity in inferior frontal regions was associated with lower parahippocampal as well as higher middle frontal activity in older adults. Frontal connectivity during encoding correlated significantly with later memory performance. Daselaar et al. (2003) observed reduced activity in the perirhinal/parahippocampal cortex during incidental encoding of words in older participants. They further discovered a trend for a reduced lateralization of prefrontal activity in the older group. Activity in the perirhinal/parahippocampal cortex during encoding is crucial for later retrieval (Strange et al., 2002) and reduced activity in these regions in older adults might indicate an encoding deficit (Daselaar et al., 2003). Sambataro et al. (2012) observed decreased activity in the left hippocampus as well as increased activity in bilateral prefrontal cortical regions in older participants compared to younger ones during incidental encoding of scenes. Similarly, Fischer et al. (2010) found decreased hippocampal activity in older adults compared to younger adults during encoding of fearful faces accompanied by decreased activity in the right amygdala as well as increased activity in the left insular cortex and the right superior frontal gyrus. In Kensinger and Schacter (2008), successful encoding was associated with increased activations in the bilateral hippocampus and the bilateral parahippocampus in younger adults, while it was associated with more activity in the bilateral medial, the left middle and the right inferior frontal gyrus, the right middle temporal gyrus, the right insula, and the bilateral anterior cingulate gyrus in older adults. Again, this speaks to the PASA model.

Waring et al. (2013) compared effective brain connectivity during encoding of emotional items and their background and observed stronger connectivity in frontal regions and from frontal regions to medial temporal lobe structures in older adults. These results correspond to the PASA model as well as the $\mathrm{CRUNCH}$ model (since the findings were more prominent in difficult tasks).

Wang and Giovanello (2016) observed similar activity in the hippocampus and the perirhinal cortex in both age groups, but the posterior part of the hippocampus was more active during retrieval in older adults. Another study of the same group found that the posterior hippocampus and the posterior medial cortex were stronger functionally connected in older participants (Wang et al., 2010).

Evidence for the HAROLD model provide the studies of Stebbins et al. (2002), Sambataro et al. (2012), Kalenzaga et al. (2015), and François et al. (2018). Kalenzaga et al. (2015) found increased activity in fronto-parietal regions when comparing older adults to younger ones after forming associations between words out of a sentence-filling task and autobiographical memories. Likewise, Stebbins et al. (2002) observed that older adults show less left-lateralized activity during encoding than younger adults did, especially in the superior and middle frontal gyrus. They asked participants to decide if words were abstract or concrete (deep encoding) or if the words were printed in uppercase or lowercase letters (shallow encoding). François et al. (2018) compared brain activity for remember vs. know items after encoding of line drawings. Both age groups showed increased activity during encoding in the right inferior frontal gyrus and the pre-supplementary motor area for remember compared to know items. For remember items, younger adults showed increased bilateral activity in the inferior frontal gyri as well as in the left middle temporal gyrus. Older adults showed increased activity in the left and right precuneus, the right superior temporal gyrus, and the right middle as well as superior frontal gyri. Likewise, Sambataro et al. (2012) observed increased activity in bilateral prefrontal regions in older participants compared to younger ones during incidental encoding of scenes.

Aine et al. (2005) used magnetoencephalography (MEG) to identify time-dependent changes of the magnetic field in the brain during incidental encoding processes. In their study, the participants had to decide if presented objects were larger than a television or not. The authors found similar time-dependent changes in prefrontal regions in both age groups, but elderly adults tended to produce stronger responses than younger adults did.

Stronger activity in the precuneus and the superior temporal gyrus in older adults as observed in a study by François et al. (2018) might be an indicator for a less attenuated DMN as well as an inhibited fronto-parietal network. Likewise, Sambataro et al. (2012) observed that regions related to the DMN were more active during incidental encoding of scenes in older adults compared to younger ones. The authors stated that the increased activity in the DMN reflects additional allocation of attentional resources, which supports the STAC model. Others favored increased activity in the DMN as a sign of dysregulation leading to reduced ability to control attention (Reuter-Lorenz and Park, 2010).

Saverino et al. (2016) found similar activity in the right middle occipital gyrus and the left parahippocampus in both groups during encoding of house pictures. For incidental associative encoding of objects, elderly adults exhibited decreased activity in the inferior frontal gyrus, the left precuneus, the right inferior temporal gyrus, and the left middle as well as the right posterior cingulate cortex. The authors suggested this as a sign for dedifferentiation in older adults, which means that older adults have less distinct neuronal representations for associative encoding, indicating a breakdown of functional specificity (Zelinski and Lewis, 2003). Cho et al. (2012) found similar results when they let participants decide if auditory presented words belong to a certain category or not. Older adults showed broad activation in right frontal regions (middle and inferior frontal gyrus and ventromedial prefrontal cortex) and in the DMN but also in the bilateral parahippocampus. This favors the dedifferentiation theory again, supporting that brain activity in older adults is less lateralized than in younger adults. Likewise, it might indicate that broader activity in older adults represents compensatory mechanisms. Ramanoël et al. (2015) also found more activity in older adults compared to younger adults during the categorization of indoor and outdoor scenes. Again, they 
found that the DMN is more active in older adults compared to younger adults during task execution.

Martins et al. (2014) assessed brain activity during semantic and phonological decisions (i.e., deep and shallow encoding). The contrast between these two encoding conditions revealed increased left lateralized activation (prefrontal cortex, posterior cingulate cortex, and precuneus) in younger participants. Interestingly, these regions are typically more active in older adults during compensation. Thus, when facing complex tasks (i.e., deep encoding), younger adults show increased activity in brain regions, which are associated with compensational approaches in older adults. Yet, in older adults, the semantic and phonological routes seem to merge into one single pathway. Thus, older adults seem to encode similarly during shallow and deep encoding, leading to better performance after shallow encoding but worse performance after deep encoding.

\section{DISCUSSION AND PERSPECTIVE}

This review revealed several important findings on how incidental learning changes with advancing age as well as how these changes relate to episodic memory performance.

First, episodic memory following incidental learning seems to be more impaired in older adults compared to younger adults in retrieval tasks with high cognitive load (i.e., free recall) compared to less demanding retrieval tasks (i.e., recognition; Figure 1). This is in line with a former meta-analysis, which summarized that age differences following incidental learning are present during free recall, attenuated during cued recall and are eliminated during recognition (Old and Naveh-Benjamin, 2008). There are several explanations for this finding: During free recall, older adults do less often use search strategies spontaneously to enhance retrieval (Lemaire, 2010; Cadar et al., 2018). Even if such strategies are provided, they use them less frequently than younger adults do and, consequently, their recall ability is lower (Lemaire, 2010). Furthermore, they regularly exhibit higher rates of intrusions (Kahana et al., 2005). During recognition, search strategies are not that important, which might explain why only few studies found age-related differences for recognition tasks.

Second, older adults retrieve less during free recall but the depth of processing influences the performance (at least in two out of three studies): Older adults perform comparable after incidental encoding with shallow processing (i.e., when focusing on the appearance of stimuli), while younger participants mostly outperform elderly participants after deep encoding (i.e., when focusing on the meaning of stimuli). These findings might be explained by impaired cognitive control processes in older adults and, thus, loss of attentional resources (Mather and Carstensen, 2005). Cognitive control is the ability to limit attention to goal-relevant information and inhibit, or suppress, irrelevant distraction (Houghton and Tipper, 1996). Deep processing demands directed attention to the task and, therefore, may be more affected by age-related attentional deficits than shallow processing, which demands less attentional resources (Craik and Lockhart, 1972). In sum, the results of this review favor the processing deficit hypothesis over the production deficiency hypothesis but further research might help to provide a definite statement.

Third, in recognition tasks, worse performance in elderly compared to younger participants is more likely for false alarms than for hit rates or reaction times. A higher false alarm rate in older adults also emerges after intentional encoding, which is known as the false-recognition effect (Balota et al., 1999): Older adults often intermingle distractor items for "old" items, particularly if they are semantically, phonologically, or orthographically related to previously shown items (Schmid et al., 2010). Since old/new decisions require proper monitoring abilities, a higher false alarm rate indicates a monitoring deficit. Increasing attention toward stimuli does not substantially alter the false-recognition effect (Koutstaal et al., 1999).

Fourth, we found evidence for an associative-memory deficit in older adults after incidental encoding, which tended to be larger after intentional encoding. Deficits in strategic processing, which are not required for incidental encoding seem to be responsible for this finding (Naveh-Benjamin et al., 2009).

When applying both incidental and intentional learning, age effects were more prevalent in free recall as well as recognition performance following intentional learning. There seems to be an influence of stimulus material, at least for the free recall performance: Older adults exhibit worse performance for the recall of when and what information after intentional-but not incidental-learning. However, they show impaired recall of where information for both learning conditions.

In sum, older adults perform inferior to younger adults following intentional learning as well as deep incidental learning, but they perform similar after shallow incidental learning. Tasks with high cognitive load (i.e., free recall) show more age-related impairment than less demanding tasks (i.e., recognition). A monitoring deficit in older adults seems to be responsible since intentional learning as well as deep encoding require more effort and attention (Troyer et al., 2007).

Regarding the neural correlates of incidental learning, we also found a few important findings (see Figure 3 for a summary). However, the interpretation might be limited since only one study corrected for volume differences (Stebbins et al., 2002).

First, most of the studies showed broader activity in older adults than in younger adults, mostly in the right prefrontal cortex. This is in line with the HAROLD model stating that older adults additionally activate right prefrontal areas to meet task demands (Cabeza, 2002). Since the prefrontal cortex is related to attention, increased activity in this area indicates that older participants require more attentional resources (Shing et al., 2010).

Second, the DMN is active during tasks in older adults and thus, inhibits brain areas involved in focusing and directing attention during a task. The dysregulated DMN hinders memory processes, which rely on focused attention (Shing et al., 2010). According to the STAC model, activity in frontal brain regions compensates dysregulation in order to maintain cognitive functioning (Reuter-Lorenz and Park, 2010). Thus, increased activity in the prefrontal cortex, which was continuously found 
in older adults, may compensate dysregulation in the DMN (Shing et al., 2010).

Third, less activity in the hippocampus during incidental encoding accompanies the broader frontal activity in older adults. This is in line with the PASA model stating that underactivation in the medial temporal cortex may be compensated with over-activity in the prefrontal cortex (Davis et al., 2008). During retrieval, older adults increasingly activate the posterior hippocampus, which might also indicate compensation (Gunning-Dixon et al., 2003).

Fourth, one study provides some indication why shallow encoding is well-preserved in older adults in contrast to deep encoding: Older adults show no significant brain activation difference for shallow compared to deep encoding tasks, while younger participants increase activity for the latter. This might indicate that older adults do not adapt to tasks that are more complex, which is why they show good performance in shallow tasks but worse performance in deep encoding tasks.

In sum, only few studies so far investigated how aging affects incidental learning. These studies found superior performance of younger adults in free recall tasks, particularly after intentional learning. On the contrary, older adults performed similar to younger adults in less cognitively demanding retrieval tasks (i.e., recognition), regardless of intentional or incidental encoding. Monitoring deficits in older adults might account for these findings since cognitively demanding free recall tasks need increased attentional resources. Regarding the neural correlates of incidental learning in older age, even less studies were available. These found broader activity in prefrontal regions, increased activity in the DMN during tasks, and less activity in hippocampal regions in older adults. Dysregulation of the DMN might indicate problems with monitoring, while increased

\section{REFERENCES}

Adler, D. H., Wisse, L. E. M., Ittyerah, R., Pluta, J. B., Ding, S., Xie, L., et al. (2018). Characterizing the human hippocampus in aging and Alzheimer's disease using a computational atlas derived from ex vivo MRI and histology. Proc. Natl. Acad. Sci. U.S.A. 115, 4252-4257. doi: 10.1073/pnas.1801093115

Aine, C. J., Adair, J. C., Knoefel, J. E., Hudson, D., Qualls, C., Kovacevic, S., et al. (2005). Temporal dynamics of age-related differences in auditory incidental verbal learning. Brain Res. Cogn. Brain Res. 24, 1-18. doi: 10.1016/j.cogbrainres.2004.10.024

Bäckman, L., Nyberg, L., Lindenberger, U., Li, S., and Farde, L. (2006). The correlative triad among aging, dopamine, and cognition. Current status and future prospects. Neurosci. Biobehav. Rev. 30, 791-807. doi: 10.1016/j.neubiorev.2006.06.005

Balota, D. A., Cortese, M. J., Duchek, J. M., Adams, D., Roediger, H. L., McDermott, K. B., et al. (1999). Verdical and false memories in healthy older adults and in dementia of the Alzheimer's type. Cogn. Neuropsychol. 16, 361-384. doi: 10.1080/026432999380834.

Baltes, P. B., Cornelius, S. W., Spiro, A., Nesselroade, J. R., and Willis, S. L. (1980). Integration versus differentiation of fluid/crytallized intelligence in old age. Dev. Psychol. 16, 625-635. doi: 10.1037/0012-1649.16.6.625

Broyd, S. J., Demanuele, C., Debener, S., Helps, S. K., James, C. J., and Sonuga-Barke, E. J. S. (2009). Default-mode brain dysfunction in mental disorders. A systematic review. Neurosci. Biobehav. Rev. 33, 279-296. doi: 10.1016/j.neubiorev.2008.09.002 prefrontal activity might signal compensation to account for deficits in attention.

In the future, more studies should systematically manipulate incidental encoding with different depths of processing and subsequently evaluate its effect on retrieval tasks with diverging cognitive load (i.e., free recall vs. recognition). Future studies should also consider the influence of attention and executive functions (i.e., monitoring) in more detail. We additionally suggest including both incidental and intentional encoding in future studies to allow for a direct comparison. More functional neuroimaging studies might foster our understanding of the age impact on the different stages of episodic memory and the contribution of hippocampal subregions. Importantly, these studies should account for age-related brain volume changes. For the DMN, resting-state connectivity might disentangle if increased activity is a sign of dysregulation.

\section{DATA AVAILABILITY}

No datasets were generated or analyzed for this study.

\section{AUTHOR CONTRIBUTIONS}

JP and SK contributed conception and design of the study. CW and KW performed the statistical analysis. CW wrote the first draft of the manuscript. All authors contributed to manuscript revision, read, and approved the submitted version.

\section{FUNDING}

CW was funded by the Novartis Foundation for medicalbiological research (Grant \#17C195).
Cabeza, R. (2002). Hemispheric asymmetry reduction in older adults. The HAROLD model. Psychol. Aging 17, 85-100. doi: 10.1037//0882-7974. 17.1.85

Cadar, D., Usher, M., and Davelaar, E. J. (2018). Age-related deficits in memory encoding and retrieval in word list free recall. Brain Sci. 8:211. doi: 10.3390/brainsci8120211.

Carr, V. A., Castel, A. D., and Knowlton, B. J. (2015). Age-related differences in memory after attending to distinctiveness or similarity during learning. Neuropsychol. Dev. Cogn. B Aging Neuropsychol. Cogn. 22, 155-169. doi: 10.1080/13825585.2014.898735

Carstensen, L. L., and Mikels, J. A. (2005). At the intersection of emotion and cognition: aging and the positivity effect. Curr. Direct. Psychol. Sci. 14, 117-121. doi: 10.1111/j.0963-7214.2005.00348.x

Cho, Y. W., Song, H. J., Lee, J. J., Lee, J. H., Lee, H. J., Yi, S. D., et al. (2012). Age-related differences in the brain areas outside the classical language areas among adults using category decision task. Brain Lang. 120, 372-380. doi: 10.1016/j.bandl.2011.12.013

Craik, F. I. M., and Lockhart, R. S. (1972). Levels of processing. A framework for memory research. J. Verb. Learn. Verb. Behav. 11, 671-684. doi: 10.1016/S0022-5371(72)80001-X

Damoiseaux, J. S., Beckmann, C. F., Arigita, E. S., Barkhof, F., Scheltens, P., Stam, C. J., et al. (2008). Reduced resting-state brain activity in the "default network" in normal aging. Cereb. Cortex 18, 1856-1864. doi: 10.1093/cercor/bhm207

Daselaar, S. M., Veltman, D. J., Rombouts, S. A. R. B., Raaijmakers, J. G. W., and Jonker, C. (2003). Neuroanatomical correlates of episodic encoding 
and retrieval in young and elderly subjects. Brain J. Neurol. 126, 43-56. doi: 10.1093/brain/awg005

Davachi, L. (2006). Item, context and relational episodic encoding in humans. Curr. Opin. Neurobiol. 16, 693-700. doi: 10.1016/j.conb.2006.10.012

Davis, S. W., Dennis, N. A., Daselaar, S. M., Fleck, M. S., and Cabeza, R. (2008). Que PASA? The posterior-anterior shift in aging. Cereb. Cortex 18, 1201-1209. doi: $10.1093 /$ cercor/bhm155

Duchek, J. M. (1984). Encoding and retrieval differences between young and old. The impact of attentional capacity usage. Dev. Psychol. 20, 1173-1180. doi: 10.1037/0012-1649.20.6.1173

Eysenck, M. W. (1974). Age differences in incidental learning. Dev. Psychol. 10, 936-941. doi: 10.1037/h0037263

Ferré, P., Fraga, I., Comesaña, M., and Sánchez-Casas, R. (2015). Memory for emotional words. The role of semantic relatedness, encoding task and affective valence. Cogn. Emot. 29, 1401-1410. doi: 10.1080/02699931.2014.982515

Fischer, H., Nyberg, L., and Bäckman, L. (2010). Age-related differences in brain regions supporting successful encoding of emotional faces. Cortex 46, 490-497. doi: 10.1016/j.cortex.2009.05.011

François, S., Angel, L., Salmon, E., Bastin, C., and Collette, F. (2018). The effect of ageing on the neural substrates of incidental encoding leading to recollection or familiarity. Brain Cogn. 126, 1-12. doi: 10.1016/j.bandc.2018.07.004

Fu, L., Maes, J. H. R., Varma, S., Kessels, R. P. C., and Daselaar, S. M. (2017). Effortful semantic decision-making boosts memory performance in older adults. Memory 25, 544-549. doi: 10.1080/09658211.2016.1193204

Galli, G. (2014). What makes deeply encoded items memorable? Insights into the levels of processing framework from neuroimaging and neuromodulation. Front. Psychiatry 5:61. doi: 10.3389/fpsyt.2014.00061

Grady, C. L., Protzner, A. B., Kovacevic, N., Strother, S. C., Afshin-Pour, B., Wojtowicz, M., et al. (2010). A multivariate analysis of age-related differences in default mode and task positive networks across multiple cognitive domains. Cereb. Cortex 20, 1432-1447. doi: 10.1093/cercor/bhp207

Greve, A., Cooper, E., and Henson, R. N. (2014). No evidence that 'fast-mapping' benefits novel learning in healthy older adults. Neuropsychologia 60, 52-59. doi: 10.1016/j.neuropsychologia.2014.05.011

Gunning-Dixon, F. M., Gur, R. C., Perkins, A. C., Schroeder, L., Turner, T., Turetsky, B. I., et al. (2003). Age-related differences in brain activation during emotional face processing. Neurobiol. Aging 24, 285-295. doi: 10.1016/S0197-4580(02)00099-4

Gutchess, A. H., Welsh, R. C., Hedden, T., Bangert, A., Minear, M., Liu, L. L., et al. (2005). Aging and the neural correlates of successful picture encoding. Frontal activations compensate for decreased medial-temporal activity. J. Cogn. Neurosci. 17, 84-96. doi: 10.1162/0898929052880048

Hämmerer, D., Callaghan, M. F., Hopkins, A., Kosciessa, J., Betts, M., CardenasBlanco, A., et al. (2018). Locus coeruleus integrity in old age is selectively related to memories linked with salient negative events. Proc. Natl. Acad. Sci. U.S.A. 115, 2228-2233. doi: 10.1073/pnas.1712268115

Hennessee, J. P., Knowlton, B. J., and Castel, A. D. (2018). The effects of value on context-item associative memory in younger and older adults. Psychol. Aging 33, 46-56. doi: 10.1037/pag0000202

Houghton, G., and Tipper, S. P. (1996). Inhibitory mechanisms of neural and cognitive control. Applications to selective attention and sequential action. Brain Cogn. 30, 20-43. doi: 10.1006/brcg.1996.0003

Kahana, M., Dolan, E. D., Sauder, C. L., and Wingfield, A. (2005). Intrusions in episodic recall: age differences in editing of overt responses. J. Gerontol. B. Psychol. Sci. Soc. Sci. 60, P92-P97. doi: 10.1093/geronb/60.2.p92

Kalenzaga, S., Sperduti, M., Anssens, A., Martinelli, P., Devauchelle, A., Gallarda, T., et al. (2015). Episodic memory and self-reference via semantic autobiographical memory. Insights from an fMRI study in younger and older adults. Front. Behav. Neurosci. 8:449. doi: 10.3389/fnbeh.2014.00449

Kensinger, E. A., and Schacter, D. L. (2008). Neural processes supporting young and older adults' emotional memories. J. Cogn. Neurosci. 20, 1161-1173. doi: 10.1162 /jocn.2008.20080

Kontaxopoulou, D., Beratis, I. N., Fragkiadaki, S., Pavlou, D., Yannis, G., Economou, A., et al. (2017). Incidental and intentional memory. Their relation with attention and executive functions. Arch. Clin. Neuropsychol. 32, 519-532. doi: $10.1093 /$ arclin/acx027

Koutstaal, W., Schacter, D. L., Galluccio, L., and Stofer, K. A. (1999). Reducing gist-based false recognition in older adults. Encoding and retrieval manipulations. Psychol. Aging 14, 220-237. doi: 10.1037/0882-7974.1 4.2.220

Lemaire, P. (2010). Cognitive strategy variations during aging. Curr. Dir. Psychol. Sci. 19, 363-369. doi: 10.1177/0963721410390354

Light, L. L. (1991). Memory and aging. Four hypotheses in search of data. Ann. Rev. Psychol. 42, 333-376. doi: 10.1146/annurev.ps.42.020191.002001

Lindner, I., Drouin, H., Tanguay, A. F. N., Stamenova, V., and Davidson, P. S. R. (2015). Source and destination memory. Two sides of the same coin? Memory 23, 563-576. doi: 10.1080/09658211.2014.911329

Lugtmeijer, S., de Haan, E. H. F., and Kessels, R. P. C. (2019). A comparison of visual working memory and episodic memory performance in younger and older adults. Neuropsychol. Dev. Cogn. 26, 387-406. doi: $10.1080 / 13825585.2018 .1451480$

Lustig, C., Hasher, L., and Tonev, S. T. (2010). Inhibitory control over the present and the past. Eur. J. Cogn. Psychol. 13, 107-122. doi: 10.1080/09541440126215

Martins, R., Simard, F., and Monchi, O. (2014). Differences between patterns of brain activity associated with semantics and those linked with phonological processing diminish with age. PLoS ONE 9:e99710. doi: 10.1371/journal.pone.0099710

Mason, S. E. (1979). Effects of orienting tasks on the recall and recognition performance of subjects differing in age. Dev. Psychol. 15, 467-469. doi: 10.1037/0012-1649.15.4.467

Mather, M., and Carstensen, L. L. (2005). Aging and motivated cognition. The positivity effect in attention and memory. Trends Cogn. Sci. 9, 496-502. doi: $10.1016 /$ j.tics.2005.08.005

McLaughlin, B. (1965). "Intentional" and "incidental" learning in human subjects. The role of instructions to learn and motivation. Psychol. Bull. 63, 359-376. doi: $10.1037 / \mathrm{h} 0021759$

Meade, M. E., Wammes, J. D., and Fernandes, M. A. (2018). Drawing as an Encoding Tool. Memorial benefits in younger and older adults. Exp. Aging Res. 44, 369-396. doi: 10.1080/0361073X.2018.1521432

Mitchell, D. B. (1989). How many memory systems? Evidence from aging. J. Exp. Psychol. Learn Mem. Cogn. 15, 31-49. doi: 10.1037/0278-7393.15.1.31

Mitchell, D. B., and Perlmutter, M. (1986). Semantic activation and episodic memory. Age similarities and differences. Dev. Psychol. 22, 86-94. doi: 10.1037/0012-1649.22.1.86

Moher, D., Liberati, A., Tetzlaff, J., and Altman, D. G. (2009). Preferred reporting items for systematic reviews and meta-analyses. The PRISMA statement. PLoS Med. 6:e1000097. doi: 10.1371/journal.pmed.1000097

Murty, V. P., Sambataro, F., Das, S., Tan, H. Y., Callicott, J. H., Goldberg, T. E., et al. (2009). Age-related alterations in simple declarative memory and the effect of negative stimulus valence. J. Cogn. Neurosci. 21, 1920-1933. doi: $10.1162 /$ jocn. 2009.21130

Naveh-Benjamin, M., Shing, Y. L., Kilb, A., Werkle-Bergner, M., Lindenberger, U., and Li, S. (2009). Adult age differences in memory for name-face associations. The effects of intentional and incidental learning. Memory 17, 220-232. doi: 10.1080/09658210802222183

Nyberg, L., Lövdén, M., Riklund, K., Lindenberger, U., and Bäckman, L. (2012). Memory aging and brain maintenance. Trends Cogn. Sci. 16, 292-305. doi: 10.1016/j.tics.2012.04.005

Old, S. R., and Naveh-Benjamin, M. (2008). Differential effects of age on item and associative measures of memory. A meta-analysis. Psychol. Aging 23, 104-118. doi: $10.1037 / 0882-7974.23 .1 .104$

Park, D. C., and Reuter-Lorenz, P. (2009). The adaptive brain. Aging and neurocognitive scaffolding. Ann. Rev. Psychol. 60, 173-196. doi: 10.1146/annurev.psych.59.103006.093656

Plancher, G., Gyselinck, V., Nicolas, S., and Piolino, P. (2010). Age effect on components of episodic memory and feature binding. A virtual reality study. Neuropsychology 24, 379-390. doi: 10.1037/a00 18680

Rabin, L. A., Barr, W. B., and Burton, L. A. (2005). Assessment practices of clinical neuropsychologists in the United States and Canada. A survey of INS, NAN, and APA Division 40 members. Arch. Clin. Neuropsychol. 20, 33-65. doi: 10.1016/j.acn.2004.02.005

Ramanoël, S., Kauffmann, L., Cousin, E., Dojat, M., and Peyrin, C. (2015). Age-related differences in spatial frequency processing during scene categorization. PLoS ONE 10:e0134554. doi: 10.1371/journal.pone. 0134554 
Reuter-Lorenz, P. A., and Cappell, K. A. (2008). Neurocognitive aging and the compensation hypothesis. Curr. Dir. Psychol. Sci. 17, 177-182. doi: $10.1111 /$ j.1467-8721.2008.00570.x

Reuter-Lorenz, P. A., and Park, D. C. (2010). Human neuroscience and the aging mind. A new look at old problems. J. Gerontol. B Psychol. Sci. Soc. Sci. 65, 405-415. doi: 10.1093/geronb/gbq035

Rhodes, S., Greene, N. R., and Naveh-Benjamin, M. (2019). Age-related differences in recall and recognition. A meta-analysis. PsyArXiv. doi: 10.31234/osf.io/6pvjd

Sambataro, F., Safrin, M., Lemaitre, H. S., Steele, S. U., Das, S. B., Callicott, J. H., et al. (2012). Normal aging modulates prefrontoparietal networks underlying multiple memory processes. Eur. J. Neurosci. 36, 3559-3567. doi: 10.1111/j.1460-9568.2012.08254.X

Saverino, C., Fatima, Z., Sarraf, S., Oder, A., Strother, S. C., and Grady, C. L. (2016). The associative memory deficit in aging is related to reduced selectivity of brain activity during encoding. J. Cogn. Neurosci. 28, 1331-1344. doi: 10.1162/jocn_a_00970

Schmid, J., Herholz, S. C., Brandt, M., and Buchner, A. (2010). Recall-toreject. The effect of category cues on false recognition. Memory 18, 863-882. doi: 10.1080/09658211.2010.517756

Shing, Y. L., Werkle-Bergner, M., Brehmer, Y., Müller, V., Li, S., and Lindenberger, U. (2010). Episodic memory across the lifespan. The contributions of associative and strategic components. Neurosci. Biobehav. Rev. 34, 1080-1091. doi: 10.1016/j.neubiorev.2009.11.002

Simons, J. S., and Spiers, H. J. (2003). Prefrontal and medial temporal lobe interactions in long-term memory. Nat. Rev. Neurosci. 4, 637-648. doi: $10.1038 /$ nrn 1178

Stebbins, G. T., Carrillo, M. C., Dorfman, J., Dirksen, C., Desmond, J. E., Turner, D. A., et al. (2002). Aging effects on memory encoding in the frontal lobes. Psychol. Aging 17, 44-55. doi: 10.1037/0882-7974.17.1.44

Strange, B. A., Otten, L. J., Josephs, O., Rugg, M. D., and Dolan, R. J. (2002). Dissociable human perirhinal, hippocampal, and parahippocampal roles during verbal encoding. J. Neurosci. 22, 523-528. doi: 10.1523/JNEUROSCI.22-02-00523.2002

Troyer, A. K., Graves, R. E., and Cullum, C. M. (2007). Executive functioning as a mediator of the relationship between age and episodic memory in healthy aging. Aging Neuropsychol. Cogn. 1, 45-53. doi: 10.1080/09289919408251449

Troyer, A. K., Häfliger, A., Cadieux, M. J., and Craik, F. I. M. (2006). Name and face learning in older adults. Effects of level of processing, self-generation, and intention to learn. J. Gerontol. B Psychol. Sci. Soc. Sci. 61, 67-74. doi: 10.1093/geronb/61.2.P67

Tulving, E. (2002). Episodic memory. From mind to brain. Ann. Rev. Psychol. 53, 1-25. doi: 10.1146/annurev.psych.53.100901.135114

Tulving, E. (2016). What is episodic memory? Curr. Dir. Psychol. Sci. 2, 67-70. doi: 10.1111/1467-8721.ep10770899

Wang, L., Laviolette, P., O’Keefe, K., Putcha, D., Bakkour, A., van Dijk, K. R. A., et al. (2010). Intrinsic connectivity between the hippocampus and posteromedial cortex predicts memory performance in cognitively intact older individuals. NeuroImage 51, 910-917. doi: 10.1016/j.neuroimage.2010.02.046

Wang, W., and Giovanello, K. S. (2016). The role of medial temporal lobe regions in incidental and intentional retrieval of item and relational information in aging. Hippocampus 26, 693-699. doi: 10.1002/hipo.22578

Waring, J. D., Addis, D. R., and Kensinger, E. A. (2013). Effects of aging on neural connectivity underlying selective memory for emotional scenes. Neurobiol. Aging 34, 451-467. doi: 10.1016/j.neurobiolaging.2012.03.011

Wheeler, M. E., and Ploran, E. J. (2008). "Episodic memory," in Encyclopedia of Neuroscience. eds M. D. Binder, N. Hirokawa (San Diego, CA: Elsevier/Academic Press), 1167-1172. doi: 10.1016/B978-008045046-9.00760-9

Zelinski, E. M., and Lewis, K. L. (2003). Adult age differences in multiple cognitive functions. Differentiation, dedifferentiation, or process-specific change? Psychol. Aging 18, 727-745. doi: 10.1037/0882-7974.18.4.727

Zhou, W., Hohmann, A. G., and Crystal, J. D. (2012). Rats answer an unexpected question after incidental encoding. Curr. Biol. 22, 1149-1153. doi: 10.1016/j.cub.2012.04.040

Conflict of Interest Statement: The authors declare that this study received funding from the Novartis Foundation for medical-biological research. The funder had no role in study design, data collection and analysis, decision to publish, or preparation of the manuscript.

Copyright (c) 2019 Wagnon, Wehrmann, Klöppel and Peter. This is an open-access article distributed under the terms of the Creative Commons Attribution License (CC $B Y)$. The use, distribution or reproduction in other forums is permitted, provided the original author(s) and the copyright owner(s) are credited and that the original publication in this journal is cited, in accordance with accepted academic practice. No use, distribution or reproduction is permitted which does not comply with these terms. 